\title{
An Artificial Intelligence Approach to Dyscalculia
}

\author{
Filipa Ferraz ${ }^{1}$, José Neves ${ }^{2 *}$, António Costa $^{2}$ and Henrique Vicente ${ }^{2,3}$ \\ ${ }^{1}$ Departamento de Informática, Universidade do Minho, Braga, Portugal \\ filipatferraz@gmail.com \\ ${ }^{2}$ Centro Algoritmi, Universidade do Minho, Braga, Portugal \\ \{jneves; acosta\}@di.uminho.pt \\ ${ }^{3}$ Departamento de Química, Escola de Ciências e Tecnologia, \\ Universidade de Évora, Évora, Portugal \\ hvicente@uevora.pt \\ * Corresponding author: phone: +351-934201337; fax: +351-253604471; \\ e-mail: jneves@di.uminho.pt
}

\begin{abstract}
Dyscalculia stands for a brain-based condition that makes it hard to make sense of numbers and mathematical concepts. Some adolescents with dyscalculia cannot grasp basic number concepts. They work hard to learn and memorize basic number facts. They may know what to do in mathematical classes but do not understand why they are doing it. In other words, they miss the logic behind it. However, it may be worked out in order to decrease its degree of severity. For example, disMAT, an app developed for android may help children to apply mathematical concepts, without much effort, that is turning in itself, a promising tool to dyscalculia treatment. Thus, this work focuses on the development of an Intelligent System to estimate children evidences of dyscalculia, based on data obtained on-the-fly with disMAT. The computational framework is built on top of a Logic Programming framework to Knowledge Representation and Reasoning, complemented with a Case-Based problem solving approach to computing, that allows for the handling of incomplete, unknown, or even contradictory information.
\end{abstract}

Keywords: Dyscalculia $\cdot$ Knowledge Representation and Reasoning $\cdot$ Logic Programming $\cdot$ Case-Based Reasoning $\cdot$ Similarity Analysis. 